\title{
Consumo urbano de yajé (ayahuasca) en Colombia
}

\author{
Andrea Vélez Cárdenas* , Augusto Pérez Gómez** \\ * Corporación Nuevos Rumbos. Psicóloga. \\ * Corporación Nuevos Rumbos. Director. \\ Enviar correspondencia a: \\ Corporación Nuevos Rumbos, Carrera 11, n 86-86. Bogotá, Colombia. aperez@nuevosrumbos.org
}

Recibido: 17 de Mayo de 2004 Aceptado: 20 de Septiembre de 2004

\section{RESUMEN}

El yajé es una sustancia alucinógena, que ha sido usada desde tiempos inmemoriales en las comunidades indígenas de Sur América con fines místicos, adivinatorios y religiosos. En la actualidad, esta sustancia empieza a salir de los contextos indígenas y se filtra en el contexto urbano, en donde su consumo se reviste de un significado y características propias. En el presente estudio se analizan las motivaciones asociadas al consumo de yajé en el contexto urbano. Para tal fin se diseñó una escala de evaluación de motivaciones, la cual fue validada por jueces y aplicada a 40 personas de la ciudad de Bogotá (Colombia) que han consumido el yajé en dos o más ocasiones. También se realizaron entrevistas semiestructuradas a cuatro de los sujetos participantes, con el fin de complementar y enriquecer la información obtenida por la escala.

Se encontró que en este grupo de personas las principales motivaciones que impulsan a que el consumo de yajé se repita son las de tipo terapéutico a nivel emocional, en donde el sujeto espera obtener tras el consumo bienestar psíquico, caracterizado por sentimientos de tranquilidad, paz interior, y claridad mental, así como resolver el estancamiento y encontrar soluciones y alternativas de manejo a situaciones personales.

Palabras clave: Ayahuasca, efectos, chamanismo, motivación, nuevos usos.

\section{ABSTRACT}

Yajé, a hallucinogenic substance, has been employed for centuries by the indigenous populations of South America, within a mystic and religious context. Recently, the use of yajé has spread from indigenous communities and permeated urban areas, acquiring a different meaning and special characteristics. The motivations for using yajé within an urban context are explored in this study. To this end, a scale was created to measure these motivations, which was validated by experts, and applied to 40 people in Bogotá (Colombia) who had taken yajé on two or more occasions. In addition, there were semistructured interviews of four of the individuals taking part, with the objective of complementing and broadening the information obtained from the scale

It was found that the primary motivations in this group for the repeated use of yajé were those of a therapeutic kind at an emotional level, where the subject hopes by taking yajé to reach psychic well-being, characterised by feelings of tranquillity, inner peace and mental clarity, in addition to the ability to resolve personal problems and find alternatives to dealing with personal situations.

Key words: Ayahuasca, effects, shamanism, motivation, new use.

to de la cosecha, y también para sanar el cuerpo y el alma, para de esta forma alcanzar una evolución espiritual; en palabras de Shultes (1982), el yajé sería considerado como "la gran medicina".

Aunque es una sustancia relativamente nueva dentro de la sociedad urbana (aparece apenas en la segunda mitad del siglo XX), se está dando, dentro de la cultura occidental, un creciente interés por acceder a los estados modificados de conciencia por medio de ella. En este sentido, y con base en el conocimiento del rápido crecimiento y de la difusión del consumo 
de yajé, así como de la consecuente ampliación de los contextos que dan lugar a los itinerarios terapéuticos que vinculan sanadores y pacientes, es posible entender este fenómeno como un 'sistema emergente de curación ritual', en donde cada uno encuentra diversas maneras de remediar sus problemas (p.e., el ejercicio, las dietas, la Nueva Era, el yoga (Uribe, 2001).

El presente estudio está dirigido a buscar un entendimiento de las motivaciones que llevan a las personas a consumir yajé en un contexto urbano.

\section{¿QUE ES EL YAJÉ?}

El yajé o ayahuasca' (Banisteriopsis caapi) es un bejuco selvático que se da en el piedemonte amazónico de Colombia, Perú y Ecuador. Considerado como una planta sagrada, constituye la clave del conocimiento empírico de todo el saber médico tradicional de la Amazonía. Generalmente suele darse el mismo nombre al bejuco y a la bebida; sin embargo, esto puede prestarse para confusiones debido a que muchas personas creen que el yajé es el liquido resultante de la cocción de la planta, y no saben que los efectos alucinógenos no proceden de ella sino de otras especies vegetales ricas en triptaminas que se añaden al bebedizo; es decir el yajé, al tiempo que es uno de los principales componentes de la poción, es también la decocción purgativa producto de la mezcla de varias plantas psicotrópicas.

Desde la perspectiva química y farmacológica, se sabe que para que el resultado de la decocción sea realmente psicoactivo es imprescindible que, a la liana ayahuasca, cuyo principio activo más importante es la harmina, perteneciente a la clase química de los alcaloides indólicos conocidos como beta-carbolinas (Ott, 1997), se añada otra planta que sea la fuente de la dimetiltriptamina (DMT) (principal responsable de la experiencia alucinatoria); ninguno de estos componentes por separado produce efectos alucinógenos consumido oralmente. Los ß-carbolinos son inhibidores de la monoaminoxidasa (IMAOs) reversibles. Ellos permiten activar, por vía oral, y aumentar la duración y la intensidad de los efectos de la DMT, es decir, estas sustancias actúan impidiendo la acción de la enzima monoaminoxidasa (MAO), la cual metaboliza o descompone aminas simples como el DMT, cuando son consumidas oralmente (Shultes, 1982).
Aun cuando el yajé es considerado como un potente alucinógeno que contiene un principio activo controlado o prohibido legalmente, no se puede asimilar a una 'droga' común o clásica como el alcohol o la cocaína, ya que su consumo recreativo es extremadamente raro debido tanto a efectos como diarrea y vómito, como a su sabor, que es en extremo desagradable. La norma general es un uso dentro de un contexto ritual y con un objetivo terapéutico y/o espiritual, en el cual participan hombres, mujeres e incluso niños, ya que no parece crear dependencia y hasta ahora no se han observado consecuencias adversas; esto no significa que las consecuencias negativas no puedan hacerse evidentes en un futuro, si el consumo pasa de concentrarse en una elite urbana y bajo condiciones relativamente ritualizadas, a generalizarse a un colectivo mayor, motivado por razones diferentes y sin ningún tipo de control. El hecho de que esta sustancia genere sensaciones de paz y bienestar, puede ser por si mismo un factor determinante para generar una adicción de tipo psicológico, en la que la persona busque escapar de su realidad y de las situaciones conflictivas que debe enfrentar, para refugiarse en un estado de tranquilidad y una realidad diferente. El consumo no controlado del yajé representa peligros potenciales, ya que estamos hablando de una sustancia toxica que puede provocar un envenenamiento a corto plazo; aun se desconocen los efectos y consecuencias que esta sustancia pueda ocasionar por un consumo indebido a mediano y largo plazo, pero es posible que tomas de yajé incontroladas, mezclando la sustancia con otro tipo de drogas psicocativas, podrían generar un problema de salud publica, similar al caso del LSD y del éxtasis, que inicialmente fueron consideradas como útiles en el campo de la psicoterapia.

\section{EFECTOS DEL YAJÉ}

Es importante tener en cuenta las diferencias individuales, debido a que con el mismo preparado, la misma dosis y en la misma sesión, los efectos pueden variar sustancialmente entre los diversos participantes, pasando así desde una ausencia total de efectos hasta una auténtica "chuma" (o borrachera) con elaboradas 'pintas' (experiencias alucinatorias). Así como los efectos varían entre sujetos, también pueden variar en una misma persona de una experiencia a otra, aun con la misma dosis y preparación de otras tomas anteriores; es decir, el sujeto puede manifestar una

\footnotetext{
El término ayahuasca proviene de la lengua quechua, popular etnia tradicional que habita los Andes. Ayahuasca viene a significar: "liana que lleva a visitar a los muertos", dado que los quechuas creían -y creen- que cuando se está bajo el efecto psicoactivo de la ayahuasca se tienen visiones del mundo habitado por los espíritus de los antepasados (Fericgla, 2000).
} 
asombrosa variación en la respuesta a la ingestión de yajé en diferentes sesiones. (Shultes, 1982).

En general, es posible identificar tres grandes etapas durante la toma de yajé. La primera de ellas es la purga, en donde a través del vomito y la diarrea se busca producir una limpieza y desintoxicación del cuerpo y del alma (desintoxicación emocional, según la cultura tradicional indígena) que prepara al individuo para "la pinta", fenómeno alucinatorio que puede empezar con figuras sencillas y geométricas (fosfenos) y terminar con elaboradas imágenes que se entretejen entre sí logrando una cierta continuidad. La última etapa identificable, sería el estado de bienestar que alcanza el individuo durante los días posteriores a la toma.

Los efectos pueden ser displacenteros o no; en general la etapa de la purga suele ser poco placentera por obvias razones. Mientras tanto la pinta puede estar acompañada de imágenes totalmente agradables, que transmitan paz y tranquilidad o, por el contrario, se pueden presentar imágenes terroríficas que intranquilicen al sujeto y lo pongan en un estado de desesperación y ansiedad.

Algunas pre-condiciones pueden alterar o afectar los efectos producidos por la toma de yajé. Entre ellas se encuentran la situación emocional y afectiva en la que se halla la persona, la cual puede llegar a potenciar o neutralizar los efectos del yajé, sea en forma consciente o inconsciente. También la voluntad del participante, la confianza, su entrega a la experiencia, la proximidad de un trauma psicológico, y su compromiso con el curandero y con el grupo, pueden afectar los resultados. Por otro lado, las condiciones ambientales en que se realice la sesión, el control de la luz, los sonidos, los olores y la postura del sujeto, son elementos que pueden modificar profundamente el efecto del yajé. (Palma, 1996.)

\section{Efectos Fisiológicos}

El principal efecto físico identificable es la "purga", fenómeno que se manifiesta aproximadamente $30 \mathrm{mi}$ nutos después de consumir la bebida y que se caracteriza por una "limpieza del cuerpo" que se ve reflejada en náuseas, vómito y defecación de tipo violento (Shultes, 1982).

\section{Efectos Alucinógenos}

El yajé, por su naturaleza alucinógena, puede producir alteraciones en la percepción del tiempo, el espacio, de sí mismo o los demás, así como también generar alucinaciones principalmente en el campo visual, aunque también se puede involucrar cualquier modalidad perceptual, ya sea a nivel auditivo, táctil y algunas veces también a nivel del gusto y el olfato. Entre las alucinaciones que experimentan los consumidores de yajé se resaltan figuras geométricas, caleidoscópicas, imágenes selváticas, místicas o religiosas, siempre de colores muy fuertes y brillantes. Todo esto ha llevado a pensar que existe algún tipo de universalidad de las alucinaciones con independencia del contexto social o cultural del que provenga la persona que se somete a la experiencia (Reichel- Dolmatoff, 1997).

Reichel-Dolmatoff (1997) identifica tres etapas fundamentales por las cuales el sujeto atraviesa durante la experiencia visionaria o Pinta: la primera de ellas se caracteriza por la presencia de fosfenos, es decir, de figuras geométricas luminosas generalmente de formas abstractas, muy similares a las que se pueden observar a través de un caleidoscopio. La segunda fase se caracteriza por la visualización de imágenes mucho más concretas como por ejemplo animales o personas, y finalmente en la tercera fase se tiende a observar formas borrosas o difusas difícilmente identificables.

\section{Efectos psicológicos}

Con frecuencia los sujetos hablan de sensaciones místicas y telepáticas, se advierten cambios en la percepción del yo y en la experiencia de cercanía con otros y de unidad con el universo. De la misma manera, se percibe un incremento en la capacidad de interacción con uno mismo. En general los efectos cuentan con una marcada carga espiritual así como con un fuerte componente que involucra la introspección y la reflexión (Uribe, 1999)

Los estados psicológicos que el consumo de yajé generan en los individuos se pueden clasificar en cuatro grupos diferentes: En primer lugar estarían aquellos efectos que facilitan la introspección y la reflexión. En los grupos indígenas, estos efectos tienen una naturaleza colectiva en la que se permite la reafirmación de la identidad social de la comunidad; dentro de un contexto urbano, estos procesos de introspección se enfocan más hacia el individuo como tal, y le proporcionan la posibilidad de "pensarse a sí mismo", y al mismo tiempo pensar de una manera profunda sobre aspectos personales, tales como problemas o conflictos en las relaciones interpersonales. Según Naranjo (1976), las personas pueden recrear y elaborar estos conflictos de una manera muy real, llegando incluso a obtener la solución correcta. Es posible también que se presenten episodios de regresión en los cuales se favorece un retorno a fases pasadas de la vida, con la finalidad de solucionar conflictos.

En segundo lugar, se encuentran los efectos relacionados con la exaltación de facultades extrasensoriales, las cuales se relacionan generalmente con sensaciones de muerte y desdoblamiento o separación del cuerpo y el alma. Adicionalmente estos efectos tam- 
bién se ligan profundamente a experiencias telepáticas en donde los participantes entran en un supuesto contacto con personas que no están presentes o tienen visiones de eventos que sucederán en el futuro. Estos resultados se manifiestan especialmente en las comunidades indígenas, en donde el consumo de yajé es usado muchas veces con propósitos adivinatorios.

En tercer lugar, se encuentran los efectos relacionados con la espiritualidad y el misticismo, los cuales se relacionan fuertemente con la visualización de imágenes religiosas tales como santos y ángeles, así como también con la sensación de contacto o presencia de espíritus.

Por último, y como efectos a mediano plazo, es posible afirmar que a diferencia de la mayoría de las sustancias alucinógenas, el yajé se asocia con un bienestar general durante los días o semanas posteriores al consumo del mismo (Pérez et al, 2000). Según consenso aparente entre los consumidores de yajé, los efectos subjetivos producidos por esta sustancia posteriores a su consumo son muy positivos y reforzantes.

\section{CONSUMO DE YAJÉ A NIVEL URBANO}

A lo largo del tiempo el yajé ha irrumpido en contextos diferentes a los estrictamente correspondientes al indígena ritual, tales como las culturas rurales y urbanas de todos los estratos socioeconómicos. En este fenómeno se evidencia de manera clara la transformación del ritual chamánico en un acto de curanderismo popular o mejor, de "neochamanismo". A menudo dentro de estos últimos contextos se pierden elementos significativos de la ceremonia ritual propia de las comunidades tradicionales, debido al nomadismo propio del sistema

Sobre la base de un primer abordaje, no sistemático, los autores de este trabajo sugieren que los motivos por los cuales las personas deciden probar el yajé son diversos y complejos, pero se pueden categorizar de la siguiente manera:

1. Sanación: El deseo de sanación tanto a nivel físico como emocional, en donde las personas atribuyen al yajé ciertos poderes mágicos que permiten la curación de casi cualquier enfermedad, así como también facilita la solución de problemas y estancamientos personales.

2. Espiritualidad: debido a que el yajé posibilita un supuesto encuentro del sujeto consigo mismo y el acceso a un conocimiento de la realidad nuevo y diferente, se usa con el fin de alcanzar cierto grado de trascendencia. Esta ascensión espiritual es entendida como un contacto cercano con una fuerza divina o superior poderosa, correspondiente al contexto cultural del cual proviene quien consume la sustancia ( por ejemplo, un acercamiento a Dios, tal y como es concebido en la religión católica, con toda la carga cultural que ello implica).

3. Interés académico: búsqueda de una profundización en temas de origen indígena, estados modificados de conciencia y consumo de sustancias enteógenas como estrategia para alcanzar un mayor conocimiento por medio de la experiencia propia.

4. Curiosidad: El único interés que se persigue es tener experiencias nuevas. Es simplemente un ensayo en donde lo que se busca es probar si "eso si sirve para algo".

Una reconocida autoridad en el tema (Zuluaga, 1999) propuso una categorización diferente con respecto a las nuevas formas de utilización del yajé en la cultura moderna: En primer lugar contempla al curanderismo, identificado como aquellas prácticas llevadas a cabo por mestizos, campesinos y hombres blancos que habitan el piedemonte amazónico; estas prácticas no contemplan todo el conocimiento original indígena e incorporan técnicas y conceptos procedentes de otras culturas (espiritismo, esoterismo, new age). En segundo lugar se encuentra el uso de yajé en prácticas de sincretismo religioso, en donde el consumo goza de una naturaleza religiosa y mística que deja de lado la cosmovisión indígena original. En tercer lugar está el uso de yajé como parte de programas de investigación científica dentro del área médica y psicológica. En un cuarto lugar se ubica el neochamanismo, que propone la búsqueda de nuevos paradigmas religiosos y médicos; los neochamanes generalmente son hombres con una amplia formación occidental que de alguna manera entran en contacto con el saber indígena y lo acomodan a su esquema de saberes y cultural. Finalmente se encuentra el consumo de yajé como la búsqueda de una experiencia alucinatoria.

\section{Yajé y religión}

Desde la década de 1930, aparece el uso que dan al yajé los sincretismos religiosos que han nacido en Brasil. En estos sincretismos, se fusiona la religión católica con el saber indígena, y se utiliza la bebida como pilar fundamental de sus creencias y simbolismos religiosos. Es por lo tanto muy diferente la representación simbólica dentro de este contexto, al contexto tradicional o urbano; aquí el consumo no se dirige a la sanación, es decir, los rituales no tienen un propósito terapéutico (aunque en algunos casos los efectos del consumo puedan llegar a serlo) sino que, más bien, el consumo tiene un sentido místico. Lo que se busca con estos rituales es alcanzar una expe- 
riencia sensible e inmediata con la divinidad, establecer un contacto directo con determinadas entidades sacras.

Existen en el momento dos iglesias sincréticas importantes que encuentran su esencia espiritual en el consumo de yajé: El Santo Daime y la UDV . El Santo Daime es un sincretismo que nació del cruce entre la religión cristiana, las prácticas de curación y el chamanismo de los indígenas amazónicos. Por otro lado la UDV es una corriente mucho más urbana, con participación en su mayoría de jóvenes profesionales de clases media y alta provenientes de un contexto más moderno; en este caso la ceremonia es menos festiva y se dirige hacia la búsqueda de la tranquilidad y la calma para propiciar un ambiente de meditación que permita el acceso a cuestiones trascendentales, como la profundización en conceptos espirituales tales como justicia, verdad, eternidad, el bien, el mal o el amor. La UDV se inscribe como iglesia seguidora de un cierto cristianismo originario, libre de distorsiones que a lo largo del tiempo ha impreso el alma humana. En este sentido, la UDV considera el yajé como un obsequio de Dios, un instrumento para acelerar la evolución espiritual del ser humano que ha existido desde los inicios míticos de los tiempos y que se redescubre periódicamente para el bien de la humanidad. (Fericgla, 1998).

\section{MÉTODO}

\section{Participantes}

Los participantes de la investigación fueron 40 personas adultas (de origen y formación occidental) residentes de la ciudad de Bogotá, que han consumido yajé por lo menos en dos ocasiones, dentro de un contexto urbano. El número de participantes fue bajo por la dificultad que implica establecer contacto con los consumidores, dado que generalmente son resistentes a colaborar con este tipo de estudios presumiendo que tienen un carácter policivo o prohibitivo. La muestra es heterogénea, es decir, se cuenta con sujetos de diferentes grupos de edad, sexo, nivel educativo y socioeconómico, lo cual permite establecer si las motivaciones son consistentes o varían en función de otros factores, y hallar similitudes y diferencias en cuanto a las motivaciones subyacentes dentro de cada grupo.

\section{Instrumentos}

Fue necesario utilizar diferentes instrumentos que brindaran información respecto a las motivaciones subyacentes al consumo de yajé. La información obtenida mediante los diferentes instrumentos, fue articulada entre sí con la finalidad de alcanzar un adecuado nivel de conocimiento respecto al tema, dentro de las posibilidades que ofrece el marco general de la investigación.

\section{Escala de Evaluación de Motivaciones Asociadas al Consumo de Yajé}

Debido a que actualmente no existe ningún instrumento que sirva para determinar factores motivacionales asociados al consumo de alucinógenos, particularmente al yajé, fue necesario diseñar una escala de evaluación en la cual se estimaron diversos factores relacionados a las motivaciones subyacentes y las representaciones que las personas tienen con respecto a la sustancia y que al mismo tiempo provocan que el consumo se mantenga (Apéndice A). Para determinar los diferentes factores se tuvo en cuenta la clasificación planteada anteriormente con respecto a los motivos de consumo y también la diseñada por Zuluaga (1999), relacionada con los diversos usos que se hacen del yajé.

Los factores incluidos dentro de esta escala de evaluación fueron los siguientes:

1. Motivaciones de tipo terapéutico (sanación física): El deseo de curación a nivel físico, en donde las personas atribuyen a la bebida del yajé ciertos poderes mágicos que permiten la curación de casi cualquier enfermedad.

2. Motivaciones de tipo terapéutico (sanación emocional): El deseo de curación a nivel emocional, en donde las personas atribuyen al yajé ciertas propiedades que facilitan la solución de problemas y estancamientos personales.

3. Motivaciones de tipo espiritual y/o religioso: el yajé es utilizado con frecuencia con el interés de alcanzar cierto grado de trascendencia. Por otra parte, el consumo está asociado a experiencias de naturaleza religiosa y mística (como por ejemplo en el caso de los sincretismos religiosos brasileros, Santo Daime y UDV) en donde la sustancia alucinógena se convierte en un sacramento que permite la comunicación directa con lo divino.

4. Motivación orientada a intereses de tipo académico: búsqueda de una profundización en temas de origen indígena, estado modificados de conciencia y consumo de sustancias enteógenas como estrategia para alcanzar un mayor conocimiento por medio de la experiencia propia.

5. Consumo de yajé orientado únicamente a la búsqueda de una experiencia alucinatoria.

La escala de tipo Likert que se diseñó, fue sometida a un proceso de validación por cinco jueces, dando 
como resultado final la escala definitiva que se presentó a los participantes.

Adicionalmente se agregó al instrumento una serie de preguntas que aportaron información fundamental para los objetivos que se pretenden alcanzar: encuesta demográfica y de historia de consumo de la sustancia.

\section{Entrevista Semi Estructurada}

La entrevista semi-estructurada representa un valioso instrumento que aporta información adicional a la obtenida mediante la escala de evaluación. En esta entrevista se trataron aspectos tales como situación actual del sujeto (enfermedades, crisis emocionales), las razones por las cuales el sujeto tomó yajé por primera vez y los motivos que han llevado a que repita la experiencia, la descripción de la situación de consumo (contexto, acompañante, grupo, etc), los efectos del yajé (físicos, psicológicos, alucinógenos) sobre el sujeto, elementos percibidos como agradables (reforzantes) o desagradables involucrados en la toma, representación que la persona tiene de la sustancia (qué es el yajé, funciones del mismo, beneficios que la sustancia aporta a la persona), sentimientos y pensamientos que acompañan la experiencia.

\section{Diario de Campo}

La información obtenida en las diferentes observaciones de campo que se llevaron a cabo, fue consignada en un diario de campo. Esta información representa un importante recurso que complementa los datos obtenidos a partir de la escala de evaluación y las entrevistas semi-estructuradas.

\section{Procedimiento}

Los sujetos fueron contactados por vía telefónica o personalmente, con la finalidad de establecer la disponibilidad que tenían para participar en el estudio. A cada uno de ellos se le aplicó la escala de evaluación de motivaciones asociadas al consumo de yajé, y al $10 \%$ de la muestra se le realizó la entrevista semiestructurada.

A cada uno de los participantes se le ofreció un documento de consentimiento informado en donde se garantiza la confidencialidad de la información suministrada.

\section{RESULTADOS}

\section{Descripción de la Muestra}

Esta investigación contó con la participación de 40 personas que han tomado yajé al menos dos veces, entre los cuales hay 26 hombres y 14 mujeres, que se ubican en un rango de edades entre los 18 y 63 años, siendo la media 31,6 años; es decir, la edad de consumo de yajé se concentra principalmente entre los adultos jóvenes. En cuanto al grado educativo, se puede decir que la mayor parte de los participantes se ubican en un nivel superior, es decir en el nivel Universitario, completo (30\%) o incompleto (30\%). El porcentaje de participantes cuyo grado educativo alcanza el bachillerato completo es del 22,5\%, mientras quienes no alcanzan este grado son apenas el 2,5\%. Los estudios de postgrado han sido desarrollados por el $15 \%$ de la población estudiada.

Las ocupaciones de los participantes cubren una gama muy amplia; no obstante es posible decir que en una gran proporción se relaciona con actividades de tipo profesional, lo cual corrobora los comentarios con respecto al grado educativo. Por otra parte, parece ser que la mayor acogida del consumo del yajé, en este grupo, se encuentra entre profesionales vinculados con áreas tales como el arte y las ciencias sociales, así como también los estudiantes universitarios.

En este grupo, la mayoría de personas (80\%) han tomado la sustancia entre dos y cuatro veces en toda su vida. Posiblemente, el alto porcentaje en esta categoría (2 a 4 veces), se debe por una parte a que el yajé es una sustancia que hasta el momento está empezando a reconocerse y a tener una acogida en el medio urbano, y por otro lado a la dificultad de las condiciones para acceder a esta experiencia, ya que los altos costos, la consecución de un sitio adecuado y de un chamán, y reunir un grupo de participantes, son factores que pueden influir en la frecuencia de consumo de las personas. En esta población, un $17,5 \%$ de participantes han consumido yajé entre 5 y 10 veces, y solo el 2,5\% (una persona) ha usado la sustancia en más de diez ocasiones.

Según los datos suministrados por las preguntas demográficas y de situación de consumo, es posible afirmar que en esta población específica el consumo se realiza predominantemente en las ciudades $(57,5 \%)$, aunque en algunos casos, los participantes han tenido experiencias en la selva o lugares alejados de las urbes (15\%), o en ambos contextos $(27,5 \%)$. Este hecho posiblemente se debe al creciente auge que la práctica del consumo ha tenido en los últimos años, con lo cual se han creado condiciones favorables que facilitan el consumo en las ciudades, sin necesidad de un desplazamiento hasta la selva.

Por otro lado, el consumo de yajé, para esta muestra específica, esta predominantemente enmarcado en un ambiente ritualizado en el que se cuenta con la presencia de un taita como imagen principal y guía la ceremonia. El porcentaje de personas que llevó a cabo la experiencia con un grupo sin la presencia de un chaman fue del $5 \%$, las personas que han consumido yajé en un grupo con la presencia de un taita 
y también han tenido este tipo de experiencias sin contar con la presencia de esta figura están representadas por el 7,5\% de la población; tan solo un sujeto consumió yajé solo.

\section{Descripción de las Motivaciones Asociadas al Con- sumo de Yajé}

El instrumento utilizado da cuenta de las motivaciones asociadas al consumo de yajé en el contexto urbano. El instrumento cuenta con varios tipos de pregunta que se asocian a diferentes categorías, según los cinco tipos de motivaciones contemplados (terapéutico físico, terapéutico emocional, espiritual, académico y e experiencia alucinatoria).

Con respecto a las motivaciones de tipo terapéutico a nivel físico, la mayoría de los participantes coincidieron en afirmar que el yajé tiene propiedades favorecen procesos curativos. El 47,5 \% de la población afirmó que son estos efectos terapéuticos los que los motivan en gran medida a mantener el consumo. El 52,5\% de la muestra considera que ésta sustancia les permite mantenerse en buenas condiciones físicas, a pesar de que no en todos los casos esta es la condición principal que motive al consumo, y el $82,5 \%$ busca la limpieza corporal como efecto del yajé, que favorece los procesos de sanación.

En relación con motivaciones de tipo terapéutico a nivel emocional, los participantes coincidieron en afirmar, en un alto porcentaje (84\%), que el consumo de yajé juega un papel importante en la percepción de situaciones personales, generando cambios positivos en la actitud y concepción de problemas, conflictos con otros $y$, en general, en condiciones problemáticas que afectan la vida del sujeto. De igual manera, el $80 \%$ de la población reporta que esta sustancia les permitió adquirir claridad sobre cuestiones personales, ayudando a encontrar soluciones; el yajé funcionaría en este caso como una especie de 'lupa' que permite a las personas ampliar su visión de los hechos y actuar de manera más coherente y eficaz frente a los mismos. En este sentido los efectos que tiene el yajé a nivel emocional, se convierten un factor de mucha importancia a la hora de determinar las motivaciones predominantes que promueven el consumo de la sustancia.

En cuanto a las motivaciones de tipo espiritual, el $67 \%$ de la población considera que el yajé propicia el ascender en una escala espiritual, posiblemente porque el consumo genera algún tipo de evolución a nivel físico y emocional. Sin embargo, este hecho es entendido aquí como la paz interior del ser humano, que le permite a su vez estar en paz con el mundo externo, más que como una entidad puramente simbólica o que facilite el contacto con seres sobrenaturales. En este sentido, el $70 \%$ de la población no cree que la sustancia cumpla el papel de sacramento, símbolo de creencias religiosas, diferenciando de éste modo la espiritualidad de la religión.

Con respecto a motivaciones de tipo académico, la mayoría de personas concordaron en que es posible llegar a conocer o a ampliar el conocimiento teórico que se tiene con respecto a las sustancia, a partir de su consumo, y que al mismo tiempo pueden tener acceso a contenidos teóricos de tipo antropológico y sociológico; sin embargo, ésta no es considerada como una motivación principal para mantener el consumo, sino como un beneficio complementario.

Por ultimo, la búsqueda de experiencias alucinatorias como fin único del consumo de yajé no aparece como un factor determinante en el mantenimiento del consumo: más del $80 \%$ de la población no considera que los efectos alucinógenos de la sustancia sean los que aportan mayores beneficios a sus vidas, y tampoco creen que las ceremonias de yajé puedan ser percibidas como una actividad recreativa. Definitivamente, los participantes encuentran factores que tienen mucho más peso dentro de la experiencia. Por otro lado, los efectos eméticos y purgativos de la sustancia dificultan que ésta sea buscada con fines recreativos, cuando hay otro tipo de drogas que tienen un gran potencial alucinógeno sin provocar efectos inmediatos tan desagradables.

\section{Diferencias en Categorías Motivacionales en Fun- ción de Variables demográficas y de situación de consumo}

Para determinar la posible existencia de diferencias significativas asociadas a variables como sexo, edad, etc., se diseñaron análisis estadísticos para muestras pequeñas con la ayuda de diferentes herramientas. Se utilizó un Alfa de $5 \%$. Para determinar si existen diferencias significativas en las motivaciones en función de la edad, se realizó un análisis de varianza (ANOVA), dividiendo al grupo de participantes en tres grupos según el siguiente criterio: a) aquellos que se encontraran en un rango de edad entre los 18 y 33 años, b) los que se encontraran en un rango de edad entre los 34 y 49 años y c) participantes que estuvieran entre los 50 y 65 años de edad. Según el análisis realizado, la categoría motivacional "físico" es la única que refleja diferencias significativas en función de la edad de los participantes, en donde se observa una tendencia de los sujetos que se encuentran entre los 50 y 65 años a buscar en el yajé sus efectos terapéuticos a nivel físico, mientras que el resto de grupo tiende a buscar efectos terapéuticos a nivel emocional.

Se diseñaron también análisis de varianza para otras variables como sexo, grado educativo, estrato socioeconómico, lugar del consumo y número de veces que el sujeto ha tomado yajé; sin embargo, nin- 
guna de estas variables reportó diferencias significativas para las categorías de análisis estudiadas, y por lo tanto sus resultados no fueron incluidos aquí.

También se utilizó un Chi-cuadrado, con la finalidad de determinar si existe algún tipo de dependencia entre las categorías de análisis y las variables de tipo demográfico y de situación de consumo. Este tipo de análisis mostró que el lugar de consumo y las motivaciones físicas están muy asociadas; esto significa que el sujeto al realizar el consumo en un entorno selvático, por ejemplo, puede que busque beneficios, a nivel físico, como la recuperación de dolencias y enfermedades o el mantenimiento de un buen estado de salud que probablemente en un entorno urbano no buscaría, o viceversa. Las variables conocimiento y sexo y conocimiento y compañía también son dependientes, lo cual indica que posiblemente el hecho de que una persona consuma yajé para ampliar su conocimiento teórico con respecto a la sustancia, puede variar dependiendo del género y el contexto en el cual lleve a cabo la experiencia. En este sentido, es posible decir que la relación entre genero y compañía es fácil de entender, dado que quienes acceden a este tipo de experiencias buscando un acercamiento "teórico" a la sustancia y tratando de comprender los contenidos subyacentes a la misma (profundización en temas de origen indígena, estado modificados de conciencia, etc), prefieren realizar el consumo dentro de un contexto ritual, con la compañía de un chaman, lo cual brinda muchos mas elementos que ofrecen información de la sustancia como tal y todo lo que a la misma compete, por encima de una situación en la que el consumo se dé sin la guía de un taita quien es por excelencia un experto en el conocimiento y administración de la sustancia y juega un papel protagónico dentro de la ceremonia ritual.

Con el fin de establecer si los cinco tipos de motivaciones planteados se relacionan entre sí de forma significativa, se utilizó la correlación de Pearson, teniendo en cuenta a todos los participantes ( $\underline{N}$ =40). A este respecto, es posible decir que existe una relación significativa entre las categorías espiritual y emocional, lo cual sugiere que las personas que tengan una tendencia a consumir yajé buscando que éste funcione como un elemento que les ayuda a estar mejor a nivel emocional, también buscan el yajé para propiciar una trascendencia espiritual. Muy probablemente estos sujetos encuentren en la evolución espiritual un terreno abonado para cultivar una sana dimensión emocional, o viceversa.

Del mismo modo, la categoría emocional se relaciona significativamente con la categoría física. Esto sugiere que aquellos sujetos motivados a consumir yajé por sus propiedades curativas a nivel físico, también encuentran en ésta sustancia una cura emocio- nal, promoviendo así un equilibrio entre salud física y la psicológica.

Las categorías física y emocional se relacionan de manera negativa con la categoría alucinógeno; lo cual inca que los sujetos que se ven motivados a tomar yajé por sus propiedades curativas a nivel emocional y físico, tienden a disminuir su interés en experimentar los efectos alucinógenos del yajé como objetivo principal del consumo.

\section{DISCUSIÓN Y CONCLUSIONES}

Los datos recogidos tanto por la escala de de las Motivaciones asociadas al consumo de yajé, como por la observación de la toma, y las entrevistas realizadas a consumidores de yajé, indican que este fenómeno ha trascendido la esfera tradicional, para filtrarse en contextos modernos y urbanos, adquiriendo una personalidad propia, o características propias que lo diferencian del consumo ritual tradicional, acompañado de unos significados específicos que le atribuyen sus consumidores.

Los miembros de la población estudiada, integrantes de un contexto urbano, enmarcado en la cultura occidental, han incorporado el yajé dentro de un complejo entramado de creencias en el que confluyen elementos de orígenes diversos, religión o corrientes como la Nueva Era, y además acuden a las ceremonias por razones que básicamente se relacionan con motivaciones de tipo terapéutico a nivel emocional.

El consumo se lleva a cabo predominantemente en las ciudades, hecho que probablemente se relaciona con la progresiva acogida que en los últimos años ha venido teniendo el uso de yajé y que ha ocasionado que los 'taitas' vayan más frecuentemente a la ciudad, y existan más grupos, se organicen convocatorias y se creen estrategias para convocar a las personas a dichos eventos, evitando así el desplazamientos de los consumidores hacia las selvas.

Por otra parte, se encontró también que la sustancia ha sido consumida por la mayor parte de integrantes del grupo, entre dos y cuatro veces, lo cual indica que los sujetos de la muestra posiblemente iniciaron su consumo hace poco tiempo. Por otro lado algunas veces factores como el alto costo de esta sustancia influyen en la frecuencia de consumo.

En dichas ceremonias se conservan frecuentemente elementos propios del contexto indígena; de hecho, en la mayoría de los casos se trata de rituales oficiados por taitas provenientes de la cuenca amazónica, quienes utilizan elementos típicos como música, atuendos y cantos en dialecto tradicional. Al 
mismo tiempo, puede observarse en estos procesos una hibridación cultural manifiesta en los elementos de la cultura occidental, como símbolos religiosos (imágenes de santos, crucifijos), que al lado de los tradicionales, se hacen presentes en las ceremonias.

Aunque se trata de ritos colectivos, el carácter de los procesos que se dan en las ceremonias es de tipo individual, con un fuerte componente terapéutico.

En la población estudiada, fue posible identificar características definitorias del tipo de personas que asisten a las ceremonias de yajé. Por lo general se trata de adultos con grados profesionales vinculados a las ciencias sociales, a las artes y estudiantes universitarios, de estrato medio, solteros en su mayoría.

Cabe mencionar que, según los datos obtenidos, la importancia que se da al taita o chamán dentro de las ceremonias es fundamental, cumpliendo un rol esencial en las dinámicas colectivas e individuales observadas en las tomas. Este hecho indica a su vez, que el consumo tiende a darse en condiciones ritualizadas en el que el consumo engloba una gran cantidad de motivaciones, con las cuales no cuentan otras sustancias psicoactivas que son usadas exclusivamente con fines recreativos. Cabe mencionar que en este caso el interés de los participantes por consumir la sustancia buscando únicamente una experiencia alucinatoria, es prácticamente nulo.

La mayoría de investigaciones que hasta el momento han estudiado el fenómeno del consumo de yajé en el mundo, han explorado principalmente la experiencia alucinatoria y los efectos de la sustancia a nivel fisiológico y psicológico. Los resultados presentados en este estudio van un poco más allá y arrojan información sobre una amplia gama de elementos implicados en la experiencia del yajé y el mantenimiento de la misma.

Uno de los elementos causantes del alto grado de aceptación que tiene el yajé en esta población es su asociación con procesos terapéuticos y reflexivos que hacen que la persona se sienta satisfecha con la experiencia. Esto último ha sido reportado por algunos autores (Naranjo, 1976), que señalan que este alucinógeno facilita procesos de introspección y de resolución de conflictos consigo mismo y con los demás.

Por otra parte, los efectos posteriores placenteros son elementos que propician el mantenimiento del consumo de la sustancia, y entre ellos se reportaron el bienestar a nivel físico y sentimientos de paz y tranquilidad. En general se puede decir que estos efectos se tornan en altamente deseables para esta población, lo que hace que el consumo se repita en varias ocasiones.

En cuanto a los resultados del análisis estadístico, se encontró que las motivaciones pueden cambiar sustancialmente dependiendo del rango de edad en el que se encuentra la persona. En este caso por ejemplo, se encontró que los adultos entre 50 y 65 años de edad estaban motivados mayormente al consumo en busca de los efectos terapéuticos que generan un supuesto bienestar físico. Esto probablemente se relacione con el deterioro que en muchas ocasiones sufre la salud en esta etapa de la vida, y la búsqueda de alternativas de sanación diferentes a la medicina ortodoxa. Es importante mencionar aquí que la concepción del yajé como un tipo alternativo de medicina, es simplemente un supuesto de aquellos quienes lo consumen y atribuyen estas propiedades al mismo; sin embrago nunca ha sido comprobada científicamente su eficacia como medicina para ningún tipo de enfermedad.

Es curioso ver también la dependencia entre las variables conocimiento y tipo de compañía, que sugieren que probablemente aquellas personas que quieran acceder a un conocimiento más profundo de la sustancia la consuman en condiciones ritualizadas en donde se presentan más elementos que aportan información no solo con respecto a la sustancia como tal, sino también a temas sociológicos, antropológicos e incluso relacionados con medicina alternativa.

Finalmente, se observaron relaciones significativas entre las motivaciones de tipo espiritual y emocional, lo que sugiere que el grado de vinculación a cada una de ellas tiende a aumentar de forma paralela, del mismo modo que en la relación entre las motivaciones terapéuticas a nivel físico y emocional, en donde probablemente el sujeto busca un bienestar global en los dos niveles paralelamente.

La relevancia de este estudio y de las conclusiones obtenidas radica en varios aspectos. En primer lugar, se trata de una investigación que recurre a estrategias cuantitativas y cualitativas y cuyos resultados se generaron con base en una muestra importante, en contraposición a estudios anteriores que partían de análisis de caso o grupos considerablemente más pequeños. Por otro lado, se tuvo en cuenta una dimensión que anteriormente había sido ignorada, dando como resultado una aproximación a las motivaciones asociadas al consumo de yajé en el contexto urbano.

Por tratarse de un análisis realizado desde la psicología, aporta nuevos elementos al estudio del fenómeno del consumo de yajé, que ha sido abordado en la mayoría de los casos por disciplinas diferentes que no le dan mucha importancia a la dimensión psicológica del fenómeno.

Para estudios posteriores sería interesante estudiar los efectos subjetivos a nivel físico y psicológico, así como la naturaleza de las alucinaciones en función de las motivaciones analizadas; seria también interesante indagar, si es el caso, acerca de la naturaleza de la experiencia a nivel urbano, en culturas diferen- 
tes a la occidental. De igual manera el presente estudio podría ampliarse indagando sobre otros tipos de motivaciones que se puedan asociar al consumo del yajé, y que no fueron aquí contempladas. Además, un análisis cualitativo en mayor profundidad y con una población más amplia de sujetos entrevistados podría aportar nuevos elementos al foco de estudio.

\section{REFERENCIAS}

Fericgla, J. (2000). Breve Informe Sobre La Ayahuasca. Documento obtenido en la página http://www.pangea.org/ fericgla/textos/breve.htm. 2000.

Naranjo, C. (1976). Aspectos psicológicos de la experiencia del yajé en una situación experimental. En M. Harner (comp), Alucinógenos y Chamanismo. Londres: Oxford University Press.

Ott. J. (1997). Ayahuasca y sus Análogos. Los Enteógenos Pangéicos del Nuevo Milenio. Documento obtenido en la página http://www.geocities.com/thepaganland/ ayahuasca. html.
Palma, D. (1996). Notas de campo sobre la autoexploración con ayahuasca. Documento obtenido en la página http://www.ayahuasca-wasi.com/espanol/ayahuasca. htm.

Pérez, A. et al. (2000). El libro de las drogas. Manual para la familia. Bogotá: Editorial carrera $7^{\circ}$.

Reichel- Dolmatoff, G. (1997). Chamanes de la Selva pluvial. Ensayos sobre indios Tukano del noroeste amazónico Londres: Themis Books.

Shultes, R., Hofmann, A. (1982). Plantas de Los Dioses: Orígenes del uso de los alucinógenos. Ciudad de México: Fondo de Cultura Económica.

Uribe, C. (2001) Salud y Buena Pinta. Revista Mexicana de Ciencias de la Salud 3 (3).

Uribe, T. (1999). Efectos subjetivos del yajé en función de la procedencia cultural y otras variables. Un análisis psicológico. Bogotá: Universidad de los Andes.

Weiskopf, J. (2000). ¿A usted le pinta la pinta o la pinta le pinta a usted? Visión Chamánica: Publicación sobre Etnomedicina y Chamanismo, (3), 34-38.

Zuluaga, G. (1999) La cultura del yage, un camino de Indios. Visión Chamánica: Publicación sobre Etnomedicina y Chamanismo, (1), 10-18. 


\section{Apéndice A}

Escala de evaluación de motivaciones asociadas al consumo de yajé.

A continuación usted encontrará una serie de afirmaciones relacionadas con motivaciones asociadas al consumo de yajé. Por favor marque solo una respuesta. Su respuesta debe referirse a sus propias motivaciones (es decir, a las razones por las cuales usted continúa consumiendo yajé), no a creencias u opiniones. Califique cada una de las afirmaciones según corresponda, siendo:
TA: Totalmente da acuerdo
A: De acuerdo
D: En desacuerdo
TD: Totalmente en desacuerdo.

1. El yajé constituye un remedio que favorece la recuperación de dolencias o enfermedades que padezco en la actualidad.

2. El consumo de yajé me permite encontrar soluciones y alternativas de salida a conflictos que me afectan.

3. El consumo de yajé me abre la posibilidad de ascender en una escala espiritual.

4. La experiencia del consumo del yajé me permite alcanzar un mayor conocimiento acerca de temas de origen antropológico y sociológico que se derivan del uso de esta sustancia.

5. El beneficio más importante que me proporciona el yajé es la experiencia alucinógena que obtengo con el consumo del mismo.

6. Puedo alcanzar un mayor conocimiento de la sustancia del yajé a partir de su consumo.

7. Los efectos terapéuticos a nivel físico son los que me motivan a continuar con el consumo de yajé.

8. El consumo de yajé me permite adquirir claridad sobre cuestiones personales.

9. El consumo de yajé me permite ampliar el conocimiento teórico que tengo con respecto a la sustancia.

10. El yajé me permite mantener un buen estado de salud y bienestar corporal.

11. Los efectos psicoterapéuticos son los que me motivan a continuar con el consumo de yajé.

12. El yajé constituye un poderoso sacramento, base de mis profundas creencias Místicas.

13. El consumo de yajé es una actividad recreativa que me permite tener acceso a estados modificados de conciencia.

14. La experiencia del consumo de yajé me permite alcanzar un mayor conocimiento con respecto a los temas médicos inherentes a la sustancia.

15. El consumo de yajé genera cambios positivos en la Percepción de situaciones anteriores (problemas, relaciones, conflictos con otros, etc.).

16. El consumo de yajé me permite acceder a una calidad de vida mejor, dado que promueve la mejoría de mi salud.

17. El consumo de yajé permite la mejoría en las relaciones conmigo mismo y con los demás.

18. Los efectos alucinógenos producidos por la sustancia, son los que me motivan (o me han motivado) a repetir la experiencia.

19. Busco la limpieza corporal como efecto del yajé, que favorece los procesos de sanación.

20. Mediante el consumo de yajé logro establecer un contacto cercano con Dios o una entidad espiritual.

21. El yajé constituye una practica terapéutica en la cual se facilita el diagnostico y cura de enfermedades.

22. Considero "las tomas" de yajé como sesiones psicoterapéuticas que me proporcionan bienestar de tipo psicológico.

23. Entiendo el consumo de yajé como una forma de misticismo.

24. El consumo del yajé constituye una experimentación empírica que me permite complementar el conocimiento teórico que he adquirido de la sustancia.

25. Considero que las tomas de yajé funcionan como un tipo de asesoramiento que me permite llevar mi vida de manera más adecuada.

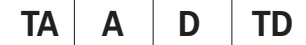


